\title{
The Role of Religion and Spirituality in Snow Leopard Conservation on and Around the Tibetan Plateau
}

\author{
Hannah Taub*, Environmental Studies
}

\begin{abstract}
As an endangered species, snow leopards are in critical and immediate danger of extinction. In the last few decades, concerted efforts on the part of conservation organizations and various governments have created stricter legal protections and designated hundreds of kilometers of land as snow leopard habitat reserves. However, given the sparsely populated, remote and rugged landscape that snow leopards roam, difficulties arise when monitoring the species and patrolling the protected areas. Tibetan Buddhists and indigenous communities inhabit land that often overlaps with snow leopard range and their spiritual traditions and practices embody an environmental ethic that puts particular emphasis on respect for animal life, specifically including snow leopards. Geographical proximity and spiritual values that align closely with conservation principles support the argument that indigenous and Tibetan Buddhist communities are valuable, underutilized resources in the efforts to protect snow leopards in and around the Tibetan Plateau. Incorporating the traditional, local knowledge of and reverence for snow leopards with scientific approaches would create a more successful and culturally-sensitive method of conservation.
\end{abstract}

\section{INTRODUCTION}

The role of various actors in wildlife conservation is complicated and highly place-specific. Stakeholders, including governments, NGOs (non-governmental organizations), and local community members, all contribute to or otherwise influence conservation in some degree. Yet the interplay among these interests often complicates the implementation of effective conservation efforts across a cohesive geographic, spatial and temporal range. It is increasingly recognized that more coordinated efforts to consider local knowledge and needs are valuable to the realization of conservation goals (DeCaro \& Stokes, 2008). Further, cultural and spiritual ideas, whether religious or indigenous, can encompass an environmental ethic that complements and lends emotional capacity to conservation rhetoric. Snow leopard conservation stands to benefit uniquely from a stronger relationship between traditional and religious communities and conservation groups. Tibetan Buddhist monks are an especially valuable potential ally for conservation groups since they inhabit areas close to snow leopard habitat and are often in positions conducive to influencing nearby communities

* Hannah Taub is from Washington, D.C., and she is a senior in the Clark Honors College, pursuing a major in Environmental Studies and minors in French and Geology. Her thesis project is focused on the land rights of Indigenous Peoples in Sweden, but she is passionate about wildlife conservation and loves big cats! On campus, Hannah contributes to Envision Journalism and Siren Magazine, and volunteers as a DJ at KWVA. Please send correspondence to htaub@uoregon.edu. 
As an apex predator and keystone species, the snow leopard is an iconic fixture of the Tibetan Plateau and the surrounding area. Further, the species is a cultural focal point for those who live within its range. From an ecological and environmental standpoint, the protection of this big cat species is absolutely crucial. Until recently, snow leopard populations faced persecution across their range, except in areas where Buddhism is prevalent (Loginova, 2016). Buddhists consider all beings to be interconnected, and animal killing is generally discouraged in communities where Tibetan Buddhism is practiced. Since the species' addition to the IUCN Red List of Threatened Species in 1972, countries that have snow leopard habitat have started various initiatives to address the issue, including the creation of national nature reserves and increased cross-border collaboration on conservation and habitat preservation. However, threats such as poaching, retaliatory killing, impacts from increased human activity on snow leopard range, and climate change continue to put stress on snow leopards and their habitat.

In their paper describing obstacles to successful conservation efforts in China, Li, Xiao and Lu (2016) highlight recent efforts to integrate local ways of life with conservation initiatives, such as programs providing compensation to herders who lose livestock to snow leopards. It is widely accepted in conservation discourse today that community engagement is best achieved through local, pre-existing organizations (Jackson and Lama, 2016). Existing evidence also shows that Buddhist monks have played an integral role in educating the community about snow leopard conservation in one conservation area in China (Li et. al, 2016). This latter point is especially intriguing, given that the modern discourse around animal conservation is heavily rooted in modern science frameworks, which tend to discount, downplay, or entirely ignore the potential role of religion, culture, and traditional ways of life in wildlife conservation, both historically and today.

\section{CONTEXT}

The Dalai Lama, the spiritual leader for Tibetan Buddhists, has highlighted the need for resistance to the current separation of religious and scientific communities, stating, "I have argued the need for and possibility of a worldview grounded in science, yet one that does not deny the richness of human nature and the validity of modes of knowing other than the scientific" (Dalai Lama, 2001). The participation of Buddhist monks on the Tibetan Plateau in snow leopard conservation is one successful example of increased inclusion of non-scientific worldviews and frameworks in scientific efforts. Clearly, conservation and the sciences have something to gain from an increased reliance on local community resources and a wider understanding of spiritual and religious concepts.

In Tibet, the issue of wildlife conservation is complicated by the political turmoil between Tibet and China, and by the remoteness of the landscape itself. However, low population density in snow leopard habitat is beneficial to their conservation because it minimizes the extent to which the big cats and their lands are interfered with and encroached upon. Additionally, the snow leopard's existence across multiple borders creates opportunities for international cooperation and increased dialogue, as countries in the region can unite over a common interest in protecting snow leopard populations (Riordan \& Shi, 2016). In the rugged and unforgiving 
snow leopard habitat, NGOs, the governments in Tibet and China, and individuals and groups that share the snow leopards' home base all provide input and work to varying degrees to protect the snow leopard. Existing studies suggest Buddhist monks, whose monasteries are often in some of the most isolated and unpopulated areas of Tibet, can play a unique role in the protection of the elusive snow leopard (Li et. al, 2014).

Given the closeness of monasteries to snow leopards in Tibet, Tibetan Buddhist monks are a critically underutilized resource in the realm of species observation for conservation purposes (Li, Yin \& Lu, 2016). Because of their elusiveness, the morphology and genetics of snow leopards remains unsatisfactorily studied and such a gap in knowledge could mean conservation strategies are not as effective as they could be (Kitchener, Driscoll \& Yamaguchi, 2016). Increased reliance on local communities for aiding in data collection could serve to improve conservation efforts in the long run. It is significant for snow leopard observation potential that "snow leopard global range overlaps substantially with the area of Tibetan Buddhism influence, including the whole Tibetan Plateau, part of Mongolia and Russia, Bhutan, Nepal, and northern India," especially since the sites of Tibetan Buddhist monasteries are often located directly within areas of snow leopard habitat (Li, Yin \& Lu, 2016). Beyond the particularly well-suited location of many Buddhist monk communities for surveillance and monitoring of the species, the spiritual aspects of the monks' way of life lends itself particularly well to snow leopard conservation.

\section{THE COMMUNITY ROLE OF BUDDHIST MONKS}

Research has highlighted how the Buddhist emphasis on the interconnectedness of all beings lends itself to the protection of wildlife ( $\mathrm{Li}$, Yin \& $\mathrm{Lu}, 2016$ ). The monks can play a leadership role in the education and inspiration of the community by rallying local herders, whose interests

may normally be focused on their livelihoods and their livestock, to consider the snow leopards in need of protection from a religious point of view. The obligation to protect nature from a spiritual standpoint is often more convincing to locals, who respect and follow the teachings of the monks, than coercive pressures from the government or environmental rhetoric from outside NGOs.

Contrary to the typical image of monastic isolation, Tibetan monks often play a positive and engaged role in the wider communities they live near. In her study titled, "The relationship between monastic and local communities: the example of Lhagang Village in Kham Minyag," author Sonam Wangmo (2016) describes the mutually beneficial relationship between monasteries and their neighboring communities:

Lay communities provide labor, supplies and goods, while in return the monastic community fulfills a wide range of the lay community's spiritual needs, in particular the performance of rituals to generate merit for laypeople, to increase their success and happiness, and to protect the community from natural disasters. 
Tibetan Buddhist monasteries are often integral institutions that provide education and various services to nearby communities. From a conservation standpoint, monasteries represent an untapped resource for disseminating information to and influencing the behavior of local communities.

Scientists studying snow leopards in the Tibetan Plateau region have expressed concern that researchers "lack sufficient understanding of current socio-ecological systems to identify ultimate and proximate drivers of pastoralist behavior, and thus policy initiatives aimed at sustainability may well fail" (Harris, 2008). Without support from the community it affects, a given policy is likely to be ineffective. The current conservation discourse supports the idea that policy design and implementation is most successful when it involves local organizations and stakeholders (Liu et. al, 2016). Such efforts at inclusion can be complicated by conflicts of interest, both within and between groups (Liu et. al, 2016).

An existing program that works to integrate local and outsider conservation efforts is the Annapurna Conservation Area Project (ACAP) in Nepal. Local community members formed Snow Leopard Conservation Committees (SLCCs), whose efforts are framed by the area's particularly cohesive society and by the non-killing principles inherent to Tibetan Buddhism, (Jackson and Lama, 2016). Such projects interweave conservation into the daily practices of the community, raising general awareness of the importance of conservation. For example, one "local religious leader was honored with a plaque for helping stop snow leopard killing and wildlife poaching by local residents," proving the local pride in and emphasis on protecting the species (Jackson and Lama, 2016). Recognition of community support for conservation goals is especially important when species conservation efforts derive from entities outside of the community (Jackson and Lama, 2016).

\section{CONSERVATION CONFLICTS}

Whereas community investment in conservation efforts is effectively supported through the framework of Tibetan Buddhism and the traditional relationship between the local community and nearby monasteries, the frameworks of the national government are sometimes at odds with these goals. The economic interests of the Chinese government sometimes override their intention to support and spearhead conservation initiatives, as is the case in the ongoing highway construction projects in the Tibetan Plateau area (Liu et. al, 2016). The religious interests of local communities are ignored and disrespected by the government project, a fact that is particularly evident in plans for the highway to cut through a site considered sacred in Tibetan Buddhism (Liu et. al, 2016). Although it is increasingly accepted that "protected area networks should integrate nature reserves managed by government with sacred lands protected culturally, especially where these two have significant overlap," there is still significant room for improvement in engaging locals and addressing their needs in conjunction with those of the snow leopard conservation work (Liu et. al, 2016). Increased awareness of the needs and potential contributions of local communities can lead to a more sustainable and culturally sensitive conservation model. Both NGOs and governments have a long way to go toward 
understanding the needs of local people who live in the remote regions inhabited by snow leopards, especially if they intend to rely on these communities to aid in conservation of the endangered big cat species.

On the Tibetan Plateau, humans and snow leopards share the landscape - but they do not always do so harmoniously, given that snow leopards often eat the livestock that many Tibetans depend on for income. Snow leopards inhabit mountainous regions of Central Asia, and are uniquely adapted to the cold climate, high altitude and rugged landscape characteristic of their terrain (Kitchener, Driscoll \& Yamaguchi, 2016). Their diet consists primarily of ungulates such as sheep and goats, which is a key point in the conflict between locals who wish to maintain and protect their livestock and conservation interest groups. Snow leopards are particularly at risk for revenge killings, since they have been observed to linger at sites where they capture prey, in potential range of angry herders (Fox \& Chundawat, 2016). It is essential that conservation groups recognize this conflict, and work must be done to balance the protection of Tibetan herders' livelihoods with that of the snow leopard. Efforts to do so are already occurring in some provinces of China, where "damage caused by snow [leopards] has received government compensation to ease conflicts with local people and to promote support for snow leopard conservation" (Riordan \& Shi, 2016). The economic loss that stems from livestock being hunted by predators can be offset by such compensation schemes, potentially lessening the incidence of revenge killings. If the needs of the community are considered in tandem with conservation goals, a more integrated and successful campaign against snow leopard extinction can be waged.

\section{CURRENT EXAMPLES OF MONASTERY INVOLVEMENT IN CONSERVATION}

In their study of monastery-based snow leopard conservation, Li et al. (2016) described how Tibetan Buddhists actively participated in conservation projects in areas where they inhabit snow leopard range. For example, local monks in the Chinese Sanjiangyuan region of the Tibetan Plateau estimated the size of the regional blue sheep population by conducting census interviews in the community ( $\mathrm{Li}$ et al. 2016). As respected community members, it is likely that the monks were able to gain access to and response from local individuals more easily than if foreign researchers had attempted to conduct the survey themselves. This study provides a practical example of how monks could aid in monitoring and data collection efforts for snow leopards.

Another example that recognized the opportunity for cooperation and synergy in snow leopard conservation by involving Tibetan monks is a 2009 study conducted by the Center for Nature and Society at Peking University in which several monasteries participated (Li et al., 2016). Notably, one of the authors of the study, published in Conservation Biology, is the premier wildlife conservation biologist working on snow leopards, George Schaller. In this project, rules were implemented designating sacred lands to each participating monastery, in which activities counter to conservation efforts were prohibited (Li et al., 2016). Such a cooperative project gives agency and direction to monasteries and Buddhist communities existing in the snow leopard range that may already be playing an inadvertent role in supporting conservation endeavors. A particularly successful realization of this potential monastic support 
for conservation efforts has occurred at the Tarthung monastery, where monks are involved in multiple conservation projects, including species monitoring and community education (Li et al., 2016). Conservation, community engagement, and religious practice are all integrated in this approach.

In protecting religious sites and sacred species, followers of and leaders within Buddhism help to maintain biodiversity and directly aid in conservation efforts. Additionally, indirect contributions to biodiversity are made through the practice of positive views and behaviors towards nature that are inherent to Buddhist philosophy (Li et al., 2016). Snow leopards are embedded in Buddhist scripture, giving their species a sacred status that increases awareness of and willingness to protect the animals among local believers. Often, these beliefs translate directly into normative behaviors conducive to the conservation of wildlife, including snow leopards. For example, Li et al. found in their study centered on China's Qinghai Province on the Tibetan Plateau that " $42 \%$ of local herders said that they did not kill wildlife because it was a sin in Buddhism" (Li et al., 2016, 203). Given that the diet of modern snow leopards relies heavily on livestock, it is understandable that many people who raise animals as a livelihood in snow leopard habitat would have a certain level of animosity towards the creatures. However, it seems these negative views are lessened given the value placed on snow leopards in Tibetan Buddhism (Liu et al., 2016).

The snow leopard is endangered for a variety of reasons, chief among them poaching, decreasing amounts of prey, and an increasingly degraded habitat (Chundaway and Habib, 2008). Conservation strategies such as nature reserves, government incentive programs, and NGOs are limited in their scope and effectiveness, especially in the remote areas of the Himalayas and the Tibetan Plateau (Li et al., 2014). For example, the Chinese Sanjiangyuan Nature Reserve on the Tibetan Plateau covers only a small portion of the almost $90,000 \mathrm{~km}^{2}$ of snow leopard habitat that spans the region. In their study of monasteries' role in snow leopard conservation in the Sanjiangyuan region, $\mathrm{Li}$ et al. found that "the 336 monasteries in the Sanjianyuan region could protect more snow leopard habitat $\left(8,342 \mathrm{~km}^{2}\right)$ through social norms and active patrols than the nature reserve's core zones," especially given that $90 \%$ of the monasteries are located within at least five kilometers of snow leopard habitat (Li et al., 2014). This evidence suggests that the pre-existing network of monasteries in Tibet has the potential to serve conservation goals on a wider scale than that of designated nature reserves. In both their spiritual tenets conducive to wildlife protection and their physical proximity to snow leopard populations, Buddhist monks provide a key resource for aiding in conservation efforts in the Tibetan Plateau region.

\section{INTEGRATING INDIGENOUS BELIEFS}

Buddhism is not the only local cultural element that is relevant to ongoing efforts to conserve snow leopard habitat and populations. The shamanism of indigenous groups in the Tibetan Plateau region is crucially connected to an understanding of and appreciation for the natural world that complements conservation efforts (Colorado \& Ryskulova, 2016). Shamans, or 
Indigenous Cultural Practitioners (ICPs), are spiritual leaders in the indigenous communities of the region. Integration of their expertise into conservation planning is slowly becoming part of the conservation discourse, due in part to the United Nations Brundtland Report and Article 21 of the Rio Earth Summit, the latter of which stressed the need for acknowledgement and use of indigenous knowledge in research ( $\mathrm{Li}$ et al, 2014). The development of The Indigenous Cultural Practitioners Statement to the Global Snow Leopard Conservation Forum in 2013 was representative of increased inclusion of indigenous perspectives to the international conservation sphere. Increasing inclusion in the international political sphere of diverse indigenous and religious viewpoints is putting pressure on the scientific community to consider these groups as potential partners in scientific and conservation endeavors.

The Kyrgyz people of Central Asia place high spiritual value on the snow leopard. (Li et al., 2014). They designate specific locations to be "sacred snow leopard sites," of which ICPs are designated Guardians ( $\mathrm{Li}$ et al., 2014). These existing belief systems create a society structured towards reverence and protection of the snow leopard. One ICP described a petroglyph at Lake Issykul in Kyrgyzstan that depicts a line connecting a human to a snow leopard as representative of the Kyrgyz reverence for and unity with snow leopards (Li et al., 2014). Kyrgyz traditional beliefs align well with those of conservationists, and incorporation of indigenous thought and cultural elements into the discourse around protecting the snow leopard could strengthen conservation efforts.

Buddhism and indigenous spirituality are particularly effective vehicles for lending an emotional element to snow leopard conservation efforts. The movement to protect the species requires more creative motivators for action, given that complete extinction is not imminent (Liu et al., 2016). Existing examples of these efforts can be seen in the proliferation of snow leopard images on stamps, banknotes and flags of various nations in and near the snow leopard habitat. Irina Loginova (2016) of the Snow Leopard Fund writes that, "The symbolism of the snow leopard can play a significant role in shaping and strengthening its positive image as a living symbol of national pride and an object of the peoples of Central Asia, and therefore contribute to its conservation." Alongside governmental campaigns similar to those employed in giant panda conservation, such as designating the snow leopard as a flagship species, the snow leopard's central roots in the area's traditional cultures and religions should be recognized and capitalized on. Rodney Jackson and Wendy Lama (2016) illuminate this point in their discussion of conservation best practices, asserting:

Beyond the goal of cultural conservation per se, protection of these mountain peoples' traditional values, religious beliefs, and sustainable livelihoods are part and parcel of snow leopard conservation...[because] without community participation, conservation efforts are incomplete.

Foreign groups would do well to call upon the expertise and opinions of local communities in snow leopard habitat in order to ensure long-term sustainability and cultural sensitivity of conservation projects. 
The Bishkek Declaration is one of the first snow leopard conservation agreements to include indigenous perspective and knowledge (Colorado \& Ryskulova, 2016). This organized plan was created in 2013 as "a global conservation strategy calling for a deep networking of sacred sites, shamans, and sacred species first within the cultural frame" that brings cultural consideration to conservation initiatives, which have primarily been science-based (Colorado \& Ryskulova, 2016). This collaboration between scientific experts and indigenous leaders represents an understanding of indigenous knowledge as a kind of environmental ethic. Legitimizing and acknowledging the indigenous perspective can lead to a more successful approach to snow leopard conservation that is culturally sensitive, holistic, and inclusive in nature.

\section{CONCLUSION}

The issue of protecting snow leopards from extinction is a challenge facing conservationists worldwide. For the people who inhabit the same lands as these big cats, there is more at stake than the ecological implications of losing a species that plays a critical role in its ecosystem. Snow leopards occupy a part of the religious and cultural frameworks of the people in the Tibetan Plateau. The indigenous peoples that have lived in the Tibetan Plateau for countless generations have developed a spiritual connection to and reverence for the snow leopard, which is apparent in their rock art and oral legends. Similarly, Tibetan Buddhists practice compassion for all living beings, and their spiritual texts and practices include a unique appreciation of and respect for the snow leopard. Members of these respective cultures and belief systems can contribute a valuable emotional element to conservation initiatives, in addition to providing their own first-hand observations and understandings of snow leopard movement and behavior. It is essential that a multi-faceted approach to saving the snow leopard be created, one that encompasses scientific, indigenous, and spiritual knowledge and practices. Not only will such integration of methods give the snow leopards a better chance of survival, but it will also acknowledge and respect the people who live side-by-side with the elusive big cats.

\section{ACKNOWLEDGMENTS}

I would like to thank Professor Hopkins for her guidance and suggestions during the research and writing process, and for introducing me to various concepts relating to the geology and biology of the Tibet region. Thanks are also due to the anonymous peer editors that provided feedback on early drafts of this paper in my Honors College class.

\section{REFERENCES}

Colorado, A. and Ryskulova, N. Shamanism in Central Asian Snow Leopard Cultures. In: McCarthy, T. ed, Snow Leopards: Biodiversity of the World: Conservation from Genes to Landscapes. London; San Diego, CA: Academic Press p. 205-09. 
DeCaro, D. and Stokes, M. 2008. Social-Psychological Principles of Community-Based Conservation and Conservancy Motivation: Attaining Goals within an Autonomy-Supportive Environment. Conservation Biology. 22 p. 1443-1451

Harris, R.B., 2008. Wildlife conservation in China preserving the habitat of China's wild west, Armonk, N.Y.: M.E. Sharpe.

Chundaway, R.S., and Habib, B. 2017. Panthera uncia Red List Assessment. International Union for Conservation of Nature and Natural Resources. http://www.iucnredlist.org/details/22732/o

Jackson, R.M. and Lama, W. B. 2016. The Role of Mountain Communities in Snow Leopard Conservation. In: McCarthy, T. ed. Snow Leopards: Biodiversity of the World: Conservation from Genes to Landscapes. London; San Diego, CA: Academic Press, p. 139148

Kitchener, A. C., Driscoll, C. A., and Yamaguchi, N. 2016. What is a Snow Leopard? Taxonomy, Morphology, and Phylogeny. In: McCarthy, T. ed. Snow Leopards: Biodiversity of the World: Conservation from Genes to Landscapes. London; San Diego, CA: Academic Press, p. 3-11

Li J., Wang, D., Yin, H., Zhaxi, D., Jiagong, Z., Schaller, G. B., Mishra, C., McCarthy, T. M., Wang, H., Wu, L., Xiao, L., Basang, L., Zhang, Y., Zhou, Y., and Lu, Z. 2014. Role of Tibetan Buddhist Monasteries in Snow Leopard Conservation. Conservation Biology, 28, pp. 87-94.

Li, J., Xiao, L., and Lu, Z. 2016. Challenges of snow leopard conservation in China. Science China. 59(6), pp. 637-639

Liu, Y., Weckworth, B., Li, J., Xiao, L., Zhao, X., Lu, Z. 2016. China: The Tibetan Plateau, Sanjiangyuan Region. In: McCarthy, T. ed. Snow Leopards: Biodiversity of the World: Conservation from Genes to Landscapes. London; San Diego, CA: Academic Press, p. 514520.

Loginova, Irina. 2016. The Snow Leopard in Symbolism, Heraldry, and Numismatics: The Order "Barys" and Title "Snow Leopard. In: McCarthy, T. ed, Snow Leopards: Biodiversity of the World: Conservation from Genes to Landscapes. London; San Diego, CA: Academic Press, p. 214-17

McCarthy, T., Mallon, David \& Nyhus, Philip J., 2016. Snow leopards, London; San Diego, CA: Academic Press

Mock, John. 2016. Snow Leopards in Art and Legend of the Pamir. In: McCarthy, T. ed, Snow Leopards: Biodiversity of the World: Conservation from Genes to Landscapes. London; San Diego, CA: Academic Press p. 210-13. 
Riordan, P., Cushman, S. A., Mallon, D., Shi, K. and Hughes, J. 2016. Predicting global population connectivity and targeting conservation action for snow leopard across its range. Ecography, 39(5). p. 419-426.

Snow Leopard Trust. 2013. Buddhist Monks Are Champions of Snow Leopard Conservation [Online]. Snow Leopard Trust. Available at: https://www.snowleopard.org/tibetanbuddhist-monks-are-champions-of-snow-leopard-conservation/

Wangmo, S. 2016. The relationship between monastic and local communities: the example of Lhagang village in Kham Minyag [Online] 47. Available at: http://emscat.revues.org/2805 